\author{
Military Technical College \\ Kobry El-Kobbah, \\ Cairo, Egypt.
}

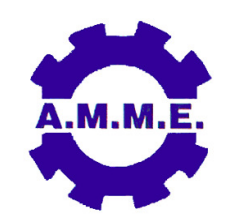

$17^{\text {th }}$ International Conference on Applied Mechanics and Mechanical Engineering.

\title{
INFLUENCE OF MICROSTRUCTURE FEATURES ON WEAR BEHAVIOUR OF Ti-64 TITANIUM ALLOY
}

\author{
K. M. Ibrahim*
}

\begin{abstract}
The mild to severe wear transition of Ti-6Al-4V titanium alloy was investigated. The correlation between microstructure and wear micro-mechanisms was also studied. Hot swaging at $900{ }^{\circ} \mathrm{C}$ was performed on the as-cast samples and thereafter two different solution treatments were applied on the swaged samples. The first treatment was applied at a temperature of $850{ }^{\circ} \mathrm{C}$ (below the $\beta$-transus temperature) for getting a bimodal structure $(\alpha+\beta)$, while the second treatment at $1050{ }^{\circ} \mathrm{C}$ was applied (above the $\beta$-transus) for getting lamellar structure $(\beta)$. The solution treated lamellar structure resulted in ultimate strength of $1335 \mathrm{MPa}$ and a hardness of $440 \mathrm{HV}_{20}$ which are significantly superior to the bimodal structure. Wear behaviour of the studied Ti64 alloy was investigated at different sliding speeds in the range of 0.5 to $2.5 \mathrm{~m} / \mathrm{s}$ with an interval of $0.5 \mathrm{~m} / \mathrm{s}$. The mild to severe wear transition was obtained at $1.5 \mathrm{~m} / \mathrm{s}$. The lowest wear rate was reported for the samples solution treated at $1050{ }^{\circ} \mathrm{C}$ due to their fine lamellae structure with high hardness. The worn surfaces of some selected samples were examined using SEM to determine the wear micro-mechanisms.
\end{abstract}

\section{KEYWORDS}

Ti-6AI-4V, Solution treatment, Microstructure, Wear, Micro-mechanisms.

\footnotetext{
* Professor, Mechanical Engineering Department, College of Engineering, Taibah University, P.O. Box 344, Al-Madinah Al-Munawarah, K.S.A. Email: khaledabouelela@yahoo.com, Mobil: + 966558526682
} 


\section{INTRODUCTION}

There are three types of titanium alloys that can be classified based on the composition of the alloy and the resultant predominant room temperature constituent's phases. These alloy types include $\alpha$ and near- $\alpha$ alloys, $\alpha+\beta$ alloys and $\beta$-alloys [1-3]. At room temperature, the $\alpha+\beta$ titanium alloys consist of hexagonal $\alpha$ phase and body centered cubic $\beta$-phase [4]. Of all the titanium alloys that have been developed, the dual-phase $(\alpha+\beta)$ Ti-6Al-4V alloy is the most commonly utilized at present, accounting for more than $50 \%$ of the titanium components $[5,6]$. It is extensively used in manufacturing of some components in aerospace and automotives applications, due to its good combination of tensile properties, fatigue strength and fracture toughness [7]. During these applications, titanium structures are often subjected to shear stress [9]. Microstructure of titanium alloy is one of the important factors controlling both tensile and wear properties [9]. The range of properties of $\alpha+\beta$ titanium alloys can be obtained by cooling rate of phase transformation from $\beta$ to $\alpha$ phases [10]. At high cooling rate (water quenching) from temperatures above $T_{\beta}$ ( $\beta$-transus temperature), martensitic reaction can occur. At low cooling rate (air cooling), $\alpha$-phase will form at grain boundaries. At intermediate cooling rates, $\alpha$-phase will be formed in a distinctly different morphology $[11,12]$.

The tribological properties of $\alpha$ and $\alpha+\beta$ titanium alloys have been investigated extensively by many researchers $[13,14]$. These Ti-alloys are insufficient in tribological performances because they are characterized by high coefficients of friction, severe adhesive wear with a high tendency to seizing and low abrasion resistance, when they slide against other engineering materials [15]. It is known that titanium alloys have poor wear resistance due to their low work hardening coefficient, low shear strength, and limited protection offered by their thin and brittle surface oxides $[16,17]$. However, wear improvements have been reported under certain sliding conditions (load, temperature, and speed) due to formation of tribologicallyprotective oxide layers. Hence, it is difficult to use titanium in friction parts. Budinski [18] conducted an extensive research on tribological properties of titanium alloys and reported that Ti6Al4V has poor abrasion resistance. Surface hardening treatments can be applied over the titanium surface components to improve the wear resistance, but often deteriorate its fatigue strength. Full hardening can enhance both wear resistance and fatigue strength [19]. Due to the discrepancy in the wear results for the Ti-64 alloy, this work aims at studying the influence of solution treatment temperature on Ti-6Al-4V samples either above or below beta transus temperature $\left(T_{\beta}\right)$ on microstructure feature and then on wear behaviour. The wear micromechanisms will be determined by examining the samples' worn surfaces using scanning electron microscopy (SEM).

\section{EXPERIMENTAL WORK}

Samples with a chemical analysis of Ti-6.3Al-4.17V-0.16Fe-0.02C-0.130-0.013N$0.0052 \mathrm{H}$ were first cast in vacuum induction furnace as rods with a diameter of 30 $\mathrm{mm}$ and $300 \mathrm{~mm}$ long. To remove the residual stress existing over the surface of the cast samples due to casting process, $2.5 \mathrm{~mm}$ was removed by turning. The final dimensions of the cast rods became $25 \mathrm{~mm}$ in diameter and $250 \mathrm{~mm}$ long which 
were suitable for hot swaging process. Swaging process was performed at $900{ }^{\circ} \mathrm{C}$ to reduce the cast bars diameter from $25 \mathrm{~mm}$ to $9 \mathrm{~mm}$ in 11 steps. Different types of microstructures were obtained by using different techniques of solution treatments. Therefore, the samples were divided into two batches for solution treatments and ageing processes. The first batch was solution treated at $1050{ }^{\circ} \mathrm{C}$ for $1 \mathrm{hr}$ (above $\mathrm{T}_{\beta}$, where $T_{\beta}$ for the studied alloy was $988{ }^{\circ} \mathrm{C}$ ) and then water quenched. While, the second batch was solution treated at $850{ }^{\circ} \mathrm{C}$ for $1 \mathrm{hr}$ (below $\mathrm{T}_{\beta}$ ) and quenched also in water. Then all samples were aged at $500{ }^{\circ} \mathrm{C}$ for $18 \mathrm{hrs}$ and then air cooled. The analysis of the different microstructures after casting, swaging and solution treatment was achieved with SEM. The metallographic sections were therefore grinded, polished and etched according to the standard methods. In order to determine the $\beta$ grains size, volume fraction of $\alpha$-phase, and $\alpha$-lamellae lath width a micro-analysis of the microstructures was carried out using PC image analyzer. The tensile properties of the investigated alloy with different microstructures were performed according to ASTM standard M8. Tensile test was carried out on threaded cylindrical samples having a gauge length and diameter of 20 and $4 \mathrm{~mm}$, respectively. Adhesion wear test was carried out using pin-on-ring Tribometer testing machine. A cylindrical test sample with $8 \mathrm{~mm}$ diameter and $12 \mathrm{~mm}$ long was fixed against a rotating stainless steel ring with a surface hardness of $63 \mathrm{HRC}$. Various rotating speeds of $0.5,1.0$, $1.5,2.0$ and $2.5 \mathrm{~m} / \mathrm{s}$ were used with an applied load of $90 \mathrm{~N}$ for $30 \mathrm{~min}$. Wear test was performed in dry condition at room temperature. Before wear testing, the sample surface was grinded and polished with an emery paper up to \#2000 to get a surface roughness within a range of $0.03 \mu \mathrm{m}$. The wear amount in each condition is the average of wear rate measured for two samples. After testing, the worn surface of some selected samples were examined using scanning electron microscopy for better understanding the wear behavior and also for determining the wear micromechanisms.

\section{RESULTS AND DISCUSSION}

\section{Microstructure Investigation}

The as-cast samples of the investigated Ti-6Al-4V alloy exhibited a microstructure consisting of $\alpha+\beta$, Fig. 1 -a. It is considered a heterogeneous structure because it contains different sizes of $\beta$-grains that ranged from 500-600 $\mu \mathrm{m}$. The $\alpha$-phase was located at the $\beta$-grain boundaries and inside the $\beta$-grains. On the other hand, the swaged samples showed very fine equiaxed $\alpha+\beta$ structure due to the high plastic deformation strain occurred by swaging process, Fig. 1-b. The $\beta$-grains size for the swaged equiaxed $\alpha+\beta$ structure was in the range of $40-50 \mu \mathrm{m}$. However, the solution treated samples showed another feature of microstructure that depends on the applied solution temperature. The samples solution treated at above $T_{\beta}\left(1050{ }^{\circ} \mathrm{C}\right)$ showed lamellae structure, and the other samples solution treated below the $T_{\beta}(850$ ${ }^{\circ} \mathrm{C}$ ) obtained bimodal structure, Fig. $1 \mathrm{c}$,d. For the samples treated at $850{ }^{\circ} \mathrm{C}$, the bimodal structure showed a distribution of interconnected equiaxed $\alpha$-grains and lamella $\alpha+\beta$ colonies (transformed $\beta$ ). The overall volume fraction of the primary $\alpha-$ phase was in the range of $50 \%$, and the average grain was in the range of $20 \mu \mathrm{m}$, Fig. 1-c. On the other side, the samples treated at $1050{ }^{\circ} \mathrm{C}$ showed a fully lamellae 
microstructure. This microstructure had an average of prior- $\beta$ grain size of $\sim 1 \mathrm{~mm}$ and a colony size of $\sim 390 \mu \mathrm{m}$ (which is referred to the parallel oriented $\alpha$-lamellae). The average $\alpha$-lamellae lath width was in the range of $1-2 \mu \mathrm{m}$, which was similar to the transformed $\beta$ in the bimodal microstructure, Fig. 1-d.

\section{Mechanical Properties}

The mechanical properties of $(\alpha+\beta)$ Ti-6Al-4V alloy can be controlled by heat treatment, which is used to adjust the microstructure constituents. This leads to the advantage that components with a wide range of mechanical properties can be produced. In this study, there are four types of microstructure features: i) as-cast large grains lamellae $\alpha+\beta$ structure, ii) very fine grains $\alpha+\beta$ swaged structure, iii) heat treated $\left(1050{ }^{\circ} \mathrm{C}\right)$ fine grains of lamellae $\alpha+\beta$ structure, and iv) heat treated $\left(850{ }^{\circ} \mathrm{C}\right)$ bimodal $\alpha+\beta$ structure. The correlation between these different microstructures and mechanical properties affecting hardness, yield and ultimate strengths, and wear resistance will be discussed.

Vickers hardness measurements were carried out to study the effect of applying hot swaging and solution treatment processes on the investigated Ti-6Al-4V alloy. The correlation between the alloy condition and hardness is shown in Fig. 2 . The as-cast structure showed the lowest hardness value of $347 \mathrm{HV}_{20}$ due its large $\beta$-grains and the heterogeneity effect in the $\alpha+\beta$ structure. By refining the as-cast $\alpha+\beta$ structure through applying a severe plastic deformation (hot swaging process), the hardness increased to $375 \mathrm{HV}_{20}$. Solution treatments and subsequent ageing at $500{ }^{\circ} \mathrm{C}$ for 18 hrs lead to an increase in hardness comparing with the as-cast and swaging conditions. The samples treated at $1050{ }^{\circ} \mathrm{C}$ showed the highest hardness value of $440 \mathrm{HV}_{20}$ due to the fineness effect in microstructure. However, the samples treated at $850{ }^{\circ} \mathrm{C}$ showed also higher hardness compared to the as-cast condition due to precipitation of fine $\alpha$-phase inside the $\alpha+\beta$ structure. Jovanovic et al. [20] obtained in their study that the hardness of Ti-6Al-4V alloy could probably be increased due to precipitation of fine $\alpha$-particles in the $\alpha+\beta$ structure from the prior $\beta$-phase.

The effect of microstructure feature on yield and ultimate strengths is shown in Fig. 3 . In this investigation, there are four different features of microstructure, where the ascast structure obtained large grains of $\alpha+\beta$ microstructure and heterogeneous distribution of $\alpha+\beta$ microstructure. Of course this heterogeneity of the $\alpha+\beta$ structure will produce low yield and ultimate strengths of $920 \mathrm{MPa}$ and $1056 \mathrm{MPa}$, respectively. By decreasing the grain size of the $\alpha+\beta$ microstructure using hot swaging at $900{ }^{\circ} \mathrm{C}$ a high amount of dislocation density will be produced inside the grains which in turn will increase the values of yield and ultimate strengths. Then, the ultimate strength value for the swaged condition will be increased to $1141 \mathrm{MPa}$ due to the fineness effect happened in microstructure as well as the existence of highly amount of dislocation density in the structure. By applying solution treatment and ageing processes of course, the microstructure is changed and then the mechanical properties will be correlated to this change in the microstructure. The samples solution treated at $1050{ }^{\circ} \mathrm{C}$ with fine lamellae structure showed the highest values of both yield and ultimate strengths. A maximum strength of $1335 \mathrm{MPa}$ was reported for the fine lamellae structure due to the homogeneity effect in the microstructure that 
happened by applying a solution treatment at $1050{ }^{\circ} \mathrm{C}$ and consequently ageing at $500{ }^{\circ} \mathrm{C}$ for $18 \mathrm{hrs}$. Actually, such treatment process decreases the dislocation density and increases the homogeneity in grain size, which in turn improve the tensile strength as compared to the as-cast and swaged conditions. An increase in ultimate strength of $279 \mathrm{MPa}$ is noticed by applying such solution treatment $\left(1050{ }^{\circ} \mathrm{C}\right)$ on the as-cast samples. This means, there is an increase in strength of about $26.4 \%$, or it may be said that there is an increase of more than quarter value of the as-cast strength by applying this solution treatment above $T_{\beta}$. On the other hand, the samples solution treated at $850{ }^{\circ} \mathrm{C}$ that have bimodal structure showed lower strength comparing to the samples solution treated at $1050{ }^{\circ} \mathrm{C}$. The yield and ultimate strengths of solution treated samples at $850{ }^{\circ} \mathrm{C}$ are $930 \mathrm{MPa}$ and $978 \mathrm{MPa}$, respectively. It may be concluded here that the solution treated lamellae structure produced higher strength compared to the bimodal one. This was obvious by comparing the strength values of solution treated samples at $1050{ }^{\circ} \mathrm{C}$, as-cast and swaged samples that have lamellae structure with different features and the samples solution treated at $850{ }^{\circ} \mathrm{C}$ with bimodal structure. These observations for the correlation between microstructure and properties of Ti-6Al-4V alloy are in agreement with other studies $[7,21,22]$.

\section{Wear Property of Ti-6Al-4V}

To improve wear resistance of titanium alloys and enable their effective use as a sliding materials, different techniques are adapted. Those are surface modification, composition adjustment, heat treatment, reinforcing the matrix with some precipitates, etc. [23]. In the present study, there is a trial to improve the tribological behavior of the titanium alloy under investigation by applying solution treatment either above or below the beta transus that followed by ageing at $500{ }^{\circ} \mathrm{C}$ for $18 \mathrm{hrs}$. The wear rate of the investigated Ti-6Al-4V alloy as a function of sliding speed for different solution temperatures is depicted in Fig. 4. Duplicate tests were conducted for each condition, and the average wear rate of the tested samples are plotted. The estimated wear rate for all conditions indicated that the wear rate increases with increasing sliding speed. Alam et al. [24] reported in their study that under a constant load of $45 \mathrm{~N}$, there was an increase in wear rate with increasing the sliding speed up to $500 \mathrm{rpm}$.

The sliding wear mechanism of Ti-6Al-4V alloy is complex because it has a complex microstructure feature. The complexity of wear mechanism of such alloy is due to the oxide layer that formed during testing, adhered, and then transformed to the counterface surface [15, 25]. This is obvious in Fig. 4, where the wear rate increases gradually with increasing sliding speed from 0.5 to $2.5 \mathrm{~m} / \mathrm{s}$. Hence, with increasing the sliding speed the amount of transferring layer from the titanium sample to the rotating stainless steel ring is increased. The microstructure feature and hardness are the key factors for determining the wear severity in each alloy condition. According to the Archard's law, the weight loss of the material is inversely proportional to the hardness value of the material [26]. This implies that the higher the hardness of the material, the lower weight loss. The present studied Ti-6Al-4V alloy in its different conditions exhibit significant difference in harness values, so that the experimental sliding wear results correlate well with Archard's law. Because the 
as-cast sample has a large grain size $(500-600 \mu \mathrm{m})$ and low hardness $\left(347 \mathrm{HV}_{20}\right)$, it is reported the highest wear rate compared to the others. On other hand, the treated samples at $1050{ }^{\circ} \mathrm{C}$ with fine grain size $(390 \mu \mathrm{m})$ and the highest hardness (440 $\mathrm{HV}_{20}$ ) showed the lowest wear rate. The heat treated samples at $850{ }^{\circ} \mathrm{C}$ showed a moderate wear rate, however it is obtained the finest grain size $(20 \mu \mathrm{m})$. Therefore, it may conclude here that the microstructure grain size does not play an important role in determining the wear rate of Ti-6Al-4V alloy. But hardness and microstructure feature (lamellae or bimodal) are considered the main factors determining the wear rate of such Ti-alloy. This result was in agreement with other previous studies [7, 9, $27,28]$. For all alloy conditions, there is a transition in wear rate with sliding speed at $1.5 \mathrm{~m} / \mathrm{s}$, where the wear rate can be classified into three zones. Zone (I), where the wear rate is relatively increased with increasing the sliding speed from $0.5-1.5 \mathrm{~m} / \mathrm{s}$ due to the first direct contact between the sample surface and the rotating ring. Therefore, the wear process in zone I can be defined as mild wear. Zone (II) from 1.5 to $2 \mathrm{~m} / \mathrm{s}$, where there was a high increase in wear rate due to increasing the inclination of the curve. Zone (II) can be characterized as severe wear mechanism. Zone (III) from 2 to $2.5 \mathrm{~m} / \mathrm{s}$, where the wear rate is still severe but less severity comparing with zone (II) due to existing of a good coinciding between the sample and the rotating ring. In both zones (II) \& (III), the wear mechanism can be also characterized as severe wear due to the high temperature generated as a result of increasing the sliding speed which will cause softening for the pin material and consequently increasing in wear rate.

The surface of wear tracks of some selected samples that were solution treated at $1050{ }^{\circ} \mathrm{C}$ because they showed the minimum wear rate at different sliding speeds $(0.5,1.5$, and $2 \mathrm{~m} / \mathrm{s})$ when they pressed against a rotating hard stainless steel ring was examined using scanning electron microscope. All images in Fig. 5 for the wear track surfaces were taken at the same magnification of X300. Evidences of continuous sliding marks with some grooves are seen on the wear tracks independently of the sliding speed. Shallow grooves and scratching were observed on the samples surfaces in case of low sliding speed $(0.5 \mathrm{~m} / \mathrm{s})$, Fig. 5 a. At medium sliding speed of $1.5 \mathrm{~m} / \mathrm{s}$, deeper sliding marks with little plastically deformed grooves are seen on the wear tracks, Fig. $5 \mathrm{~b}$. The extent of plastic deformation or ploughing is found to be higher in the case of higher sliding speed of $2 \mathrm{~m} / \mathrm{s}$ due to increasing the shear stress between the rotating ring and the sample during the wear test, Fig. 5 c. In addition, delamination wear mechanism can be seen with high sliding speed of 2 $\mathrm{m} / \mathrm{s}$ due to increasing the plastic deformation over the worn surface.

\section{CONCLUSIONS}

- As-cast coarse grains of $\alpha+\beta$ lamellar structure is broken-down into fine equiaxed structure by hot swaging at $900{ }^{\circ} \mathrm{C}$.

- Fine $\beta$-lamellar structure with $\alpha$-island obtained by solution treatment at 1050 ${ }^{\circ} \mathrm{C}$, and bimodal structure formed at $850{ }^{\circ} \mathrm{C}$. 
- Maximum ultimate strength of $1335 \mathrm{MPa}$, hardness of $440 \mathrm{HV}_{20}$, and minimum wear rate were obtained for the samples solution treated at $1050{ }^{\circ} \mathrm{C}$ due to their finest effect of the lamellae structure.

- Evidences of continuous sliding marks with plastically deformed grooves are seen on the wear tracks independently of the sliding speed. The plastic deformation over the worn surface is increased with increasing the sliding speed.

\section{REFERENCES}

[1] X. Liu, P.K. Chu, C. Ding, "Surface modification of titanium, titanium alloys, and related materials for biomedical applications", Materials Science and Engineering R, vol. 47, 2004, pp. 49-121.

[2] E. Eisenbarth, V. Velten, M. Mueller, R. Thull, J. Breme, "Biocompatibility of $\beta$-stabilizing elements of titanium alloys", Biomaterials, vol.25, 2004, pp. 5705-5713.

[3] C.T. Chang, Y.C. Du, R.K. Shiue, C.S. Chang, "Infrared brazing of high strength titanium alloys by Ti-15Cu-15Ni and Ti-15Cu-25Ni filler foils", Materials Science and Engineering A, vol. 420, 2006, pp. 155-164.

[4] L.W. Meyer, L. Krueger, K. Sommer, "Dynamic strength and failure behavior of titanium alloy Ti-6Al-4V for a variation of heat treatment", Mechanics of Time-Dependent Materials, vol. 12, 2008, pp. 237-247.

[5] T.M. Mower, "Degradation of titanium 6Al-4V fatigue strength due to electrical discharge machining", International Journal of Fatigue, vol. 64, 2014, pp. 84-96.

[6] S.M. Johnson, D. Lopez, "Effect of the cooling rate in the corrosion behavior of a hot worked Ti-6Al-4V extra-low interstitial alloy", Materials \& design, vol. 58, 2014, pp. 175-181.

[7] K.M. Ibrahim, A. Hussein, M. Abdelkawy, "Effect of Si-addition as a grain refiner on microstructure and properties of Ti-6Al-4V alloy", Transactions of Nonferrous Metals Society of China, vol. 23, 2013, pp. 1863-1874.

[8] K.M. Ibrahim, M. Mhaede, L. Wagner, "Effect of annealing temperature on microstructure mechanical properties of hot swaged CP-Ti produced by investment casting", Journal of Materials Engineering and Performance, vol. 21, 2012, pp. 114-118.

[9] K.M. Ibrahim, A.M. Elhakeem, R. Elshaer, "Microstructure and mechanical properties of cast and heat treated Ti-6.55Al-3.41Mo-1.77Zr alloy", Transactions of Nonferrous Metals Society of China, vol. 23, 2013, pp. 3517-3524.

[10] H. Shao, Y. Zhao, P. Ge, W. Zeng, "Influence of cooling rate and aging on the lamellar microstructure and fractography of TC21 titanium alloy", Metallography, Microstructure and Analysis, vol. 2, 2013, pp. 35-41.

[11] S.L. Semiatin, S.L. Knisley, P.N. Fagin, "Microstructure evolution during alpha-beta heat treatment of Ti-6Al-4V", Metallurgical and Materials Transactions A, vol. 34, 2003, pp. 2377-2386. 
[12] S. Bohemen, A. Kampa, R.H. Petrov, L.A. Kestens, J. Sietsma, "Nucleation and variant selection of secondary $\alpha$-plates in $\alpha-\beta$ Ti-alloys", Acta Materialia., vol. 56, 2008, pp. 5907-5914.

[13] M. Masmoudi, M. Assoul, M. Wery, R. Abdelhedi, F. El-Halouani, G. Monteil, "Friction and wear behavior of $\mathrm{cp} \mathrm{Ti}$ and Ti6Al4V following nitric acid passivation", Applied Surface Science, vol. 253, 2006, pp. 2237-2243.

[14] C. Courbon, F. Pusavec, F. Dumont, J. Rech, J. Kopac, "Tribological behaviour of Ti-6Al-4V and Inconel 718 under cryogenic conditions- A application to the context of machining with carbide tools", Tribology International, vol. 66, 2013, pp. 72-82.

[15] Y. Chen, T. Cheng, X. Nie, "Wear failure behavior of titanium-based oxide coatings on a titanium alloys under impact and sliding forces", Journal of Alloys and Compounds, vol. 578, 2013, pp. 336-344.

[16] A. Molineri, G. Straffelini, B. Tesi, T. Baccai, "Dry sliding wear mechanism of the Ti6Al4V alloy, Wear, vol. 208, 1997, pp. 105-117.

[17] S. Krol, W. Grzesik, Z. Zalisz, M. Hepner, "Frictional behavior of oxygen diffusion hardened titanium in dry sliding against $\mathrm{Co}-28 \mathrm{Cr}-5 \mathrm{~W}-4 \mathrm{Fe}-3 \mathrm{Ni}-$ 1Si cobalt alloy", Tribology International, vol. 37, 2004, pp. 633-643.

[18] K.G. Budinski, "Tribological properties of titanium alloys", Wear, vol. 151, 1991, pp. 203-217.

[19] T. Morita, K. Asakura, C. Kagaya, "Effect of combination treatment on wear resistance and strength of Ti-6Al-4V alloy", Materials Science \& Engineering A, vol. 618, 2014, pp. 438-446.

[20] M.T. Jovanovic, S. Tadic, S. Zec, Z. Miskovic, I. Bobic, "The effect of annealing temperatures and cooling rates and microstructure and mechanical properties of investment cast Ti-6Al-4V alloy", Materials \& Design, vol. 27, 2006, pp. 192-199.

[21] S.S. Youssef, K.M. Ibrahim, M. Abdel-Karim, "Effect of heat treatment process on tribological behavior of Ti-6Al-4V alloy", International Journal of Mechanical Engineering and Robotics Research, vol. 2, no. 2, 2013, pp. 385-394.

[22] T. Morita, K. Hatsuoka, T. Lizuka, K. Kawasaki, "Strengthening of Ti-6AI-4V alloy by short-time duplex heat treatment", Materials Transactions, vol. 46, no. 7, pp. 1681-1686.

[23] S.G. Setti, R.N. Rao, "Tribological behavior of near $\beta$ titanium alloy as a function of $\alpha+\beta$ solution treatment temperature", Materials and Design, vol. 50, 2013, pp. 997-1004.

[24] O. Alam, A.S. Haseeb, "Response of Ti-6Al-4V and Ti-24Al-11Nb alloys to dry sliding wear against hardened steel", Journal of Tribology International, vol. 35, 2002, pp. 357-362.

[25] J. Qu, P.J. Blau, T.R. Watkins, O.B. Cavin, N.S. Kulkarni, "Friction and wear of titanium alloys sliding against metal, polymer, and ceramic counterfaces", Wear, vol. 258, 2005, pp. 1348-1356.

[26] J.F. Archard, "Contact and rubbing of flat surfaces", Journal of Applied Physics, vol. 24, no. 8, 1953, pp. 981-988.

[27] S.S. Youssef, K.M. Ibrahim, M. Karim, "Effect of heat treatment process on tribological behavior of Ti-6Al-4V alloy", International Journal of Mechanical Engineering and Robotics Research, vol. 2, no. 4, 2013, pp. 385-394. 
[28] Y.S. Lee, M. Niinomi, M. Nakai, K. Narita, K. Cho, "Predominant factor determining wear properties of $\beta$-type and $(\alpha+\beta)$-type titanium alloys in metal-to-metal contact for biomedical applications", Journal of the Mechanical Behavior of Biomedical Materials, vol. 41, 2015, pp. 208-220.
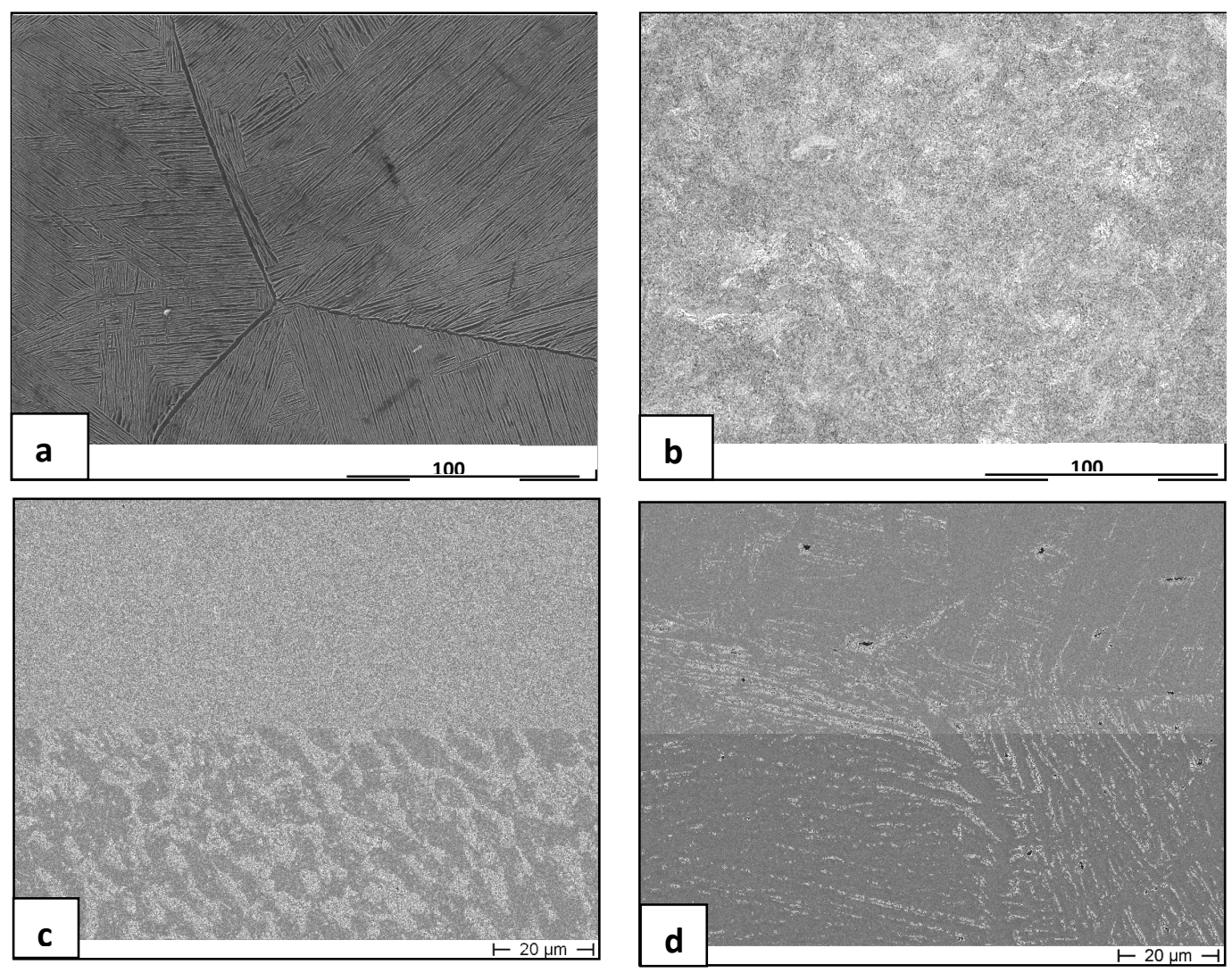

Fig. 1: Microstructure of the investigated Ti-6Al-4V alloy under different conditions a- As-cast, b- Swaged, c- ST+A at $850{ }^{\circ} \mathrm{C}, \mathrm{d}-\mathrm{ST}+\mathrm{A}$ at $1050{ }^{\circ} \mathrm{C}$.

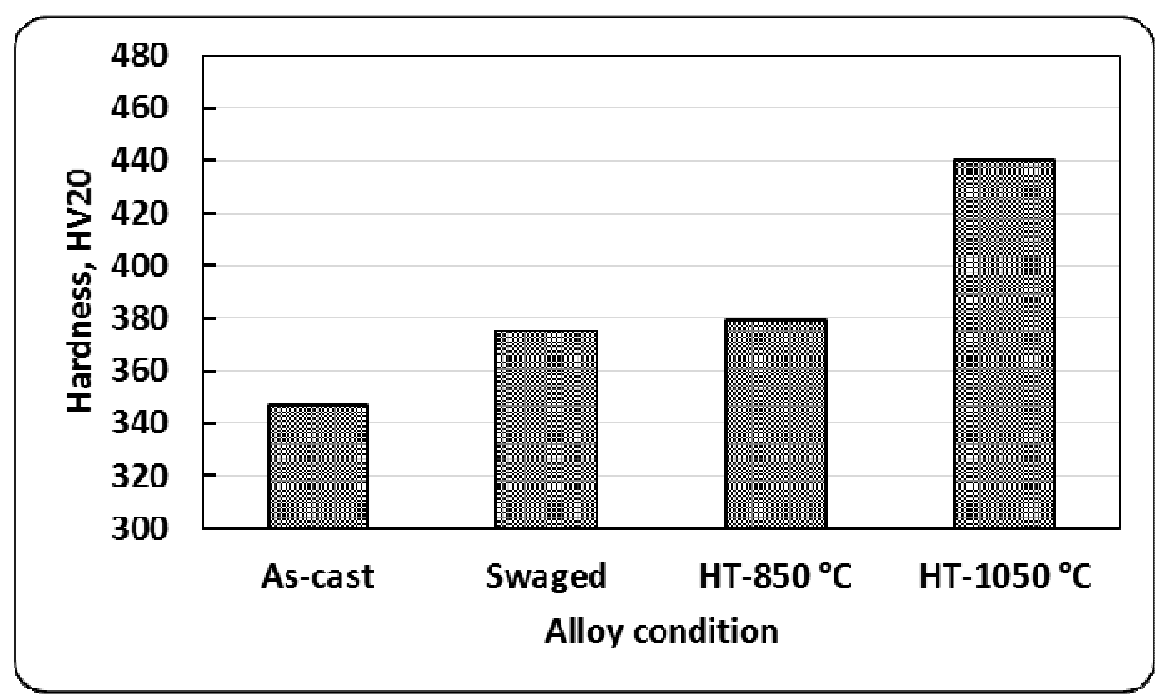

Fig. 2: The correlation between the investigated Ti-64 alloy condition and hardness. 


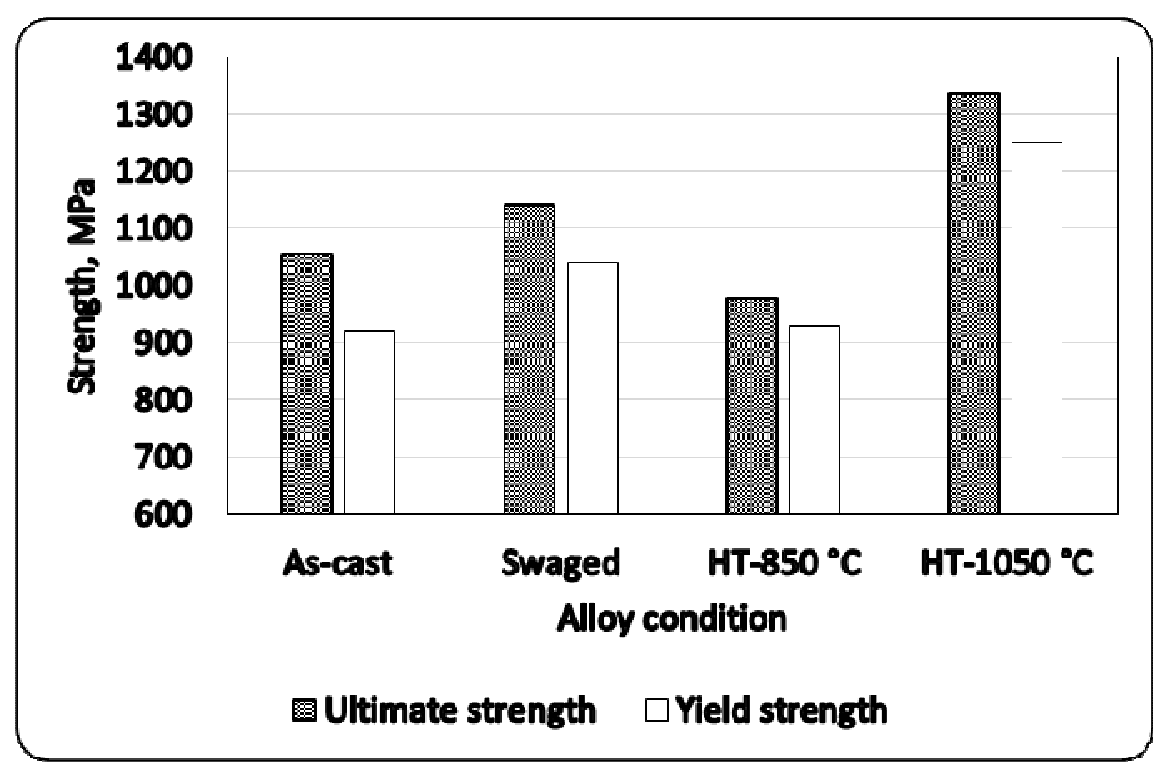

Fig. 3: The correlation between the investigated Ti-6Al-4V alloy condition and strength.

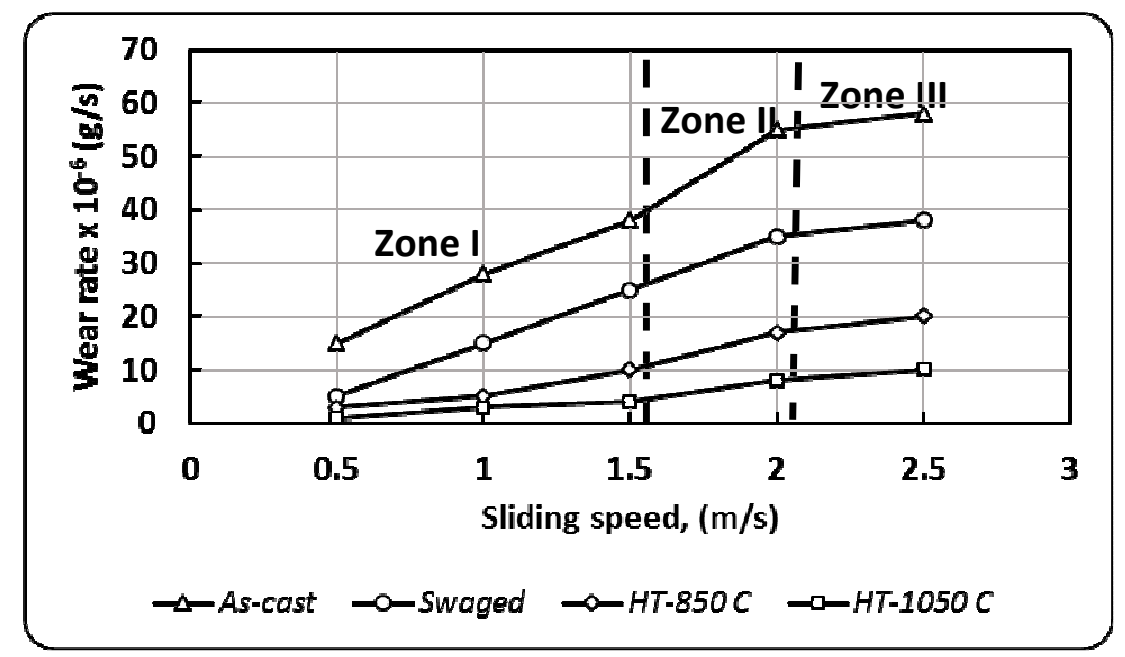

Fig. 4: Wear rate of the studied Ti-6Al-4V alloy as a function of sliding speed 

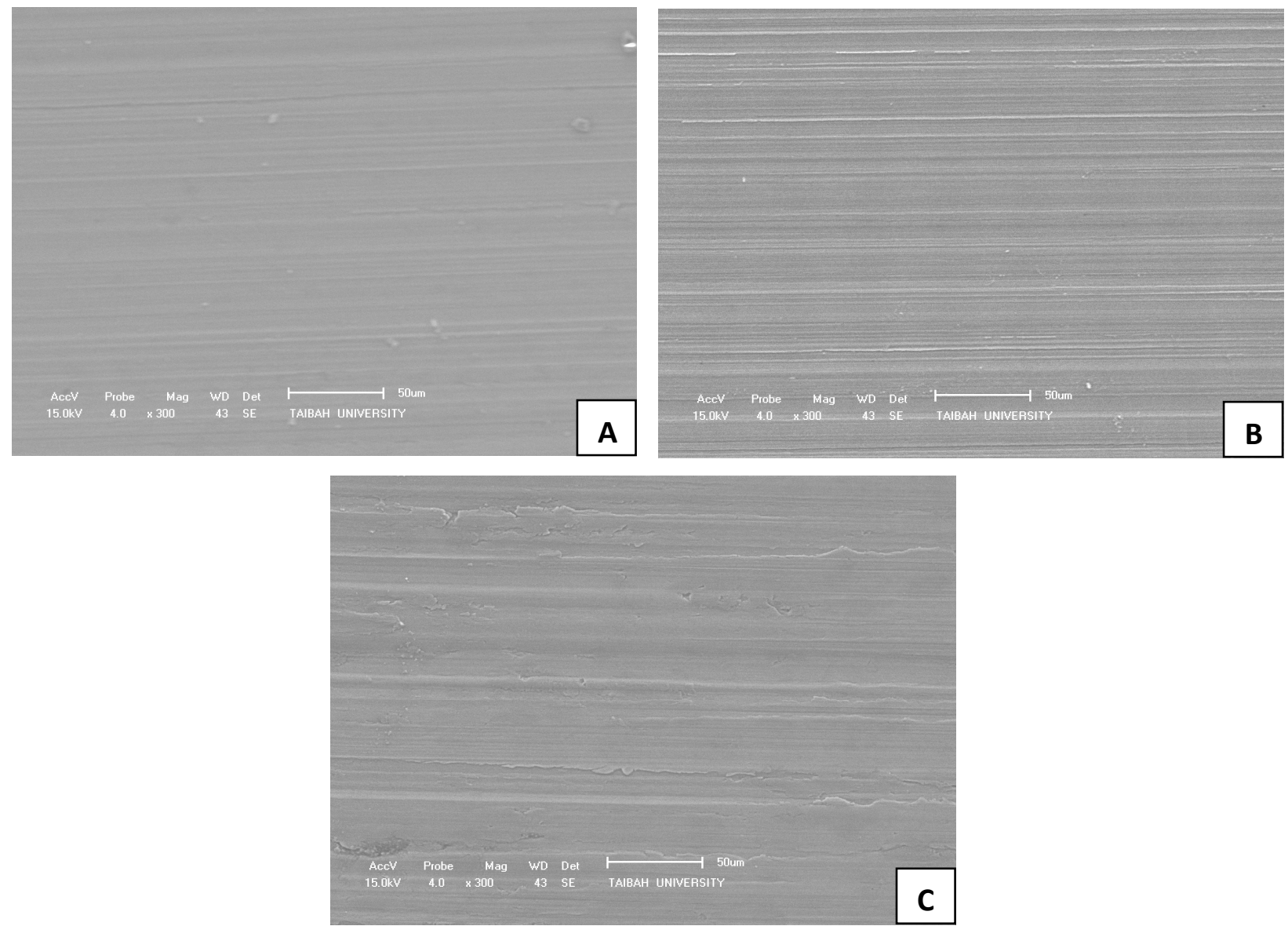

Fig. 5: SEM images of the wear track surfaces on Ti-6Al-4V samples at different sliding speeds: A- $0.5 \mathrm{~m} / \mathrm{s}$, B- $1.5 \mathrm{~m} / \mathrm{s}$, and C- $2 \mathrm{~m} / \mathrm{s}$ 